\title{
Mímesis sonora y metamorfosis estética: el siglo XIX como estadio crítico en la historia del pensamiento musical
}

Javier Campos Calvo-Sotelo

Investigador independiente, Madrid, España

javier.campos.cs@gmail.com

Recepción: septiembre 2019.

Aceptación: diciembre 2019.

\section{Resumen}

La teoría de la afinidad sónica (Campos, 2016) considera que el cerebro musical humano está modelado por la acción de sonidos recibidos desde la formación del oído, generando perfiles sonoros y estéticos en procesos miméticos integrados en la lógica evolutiva. Aplicada al ámbito de la musicología histórica, permite analizar el siglo XIX como estadio determinante de mutaciones musicales a raíz de la revolución industrial, que aplastó la quietud sonora del Antiguo Régimen con el estruendo de las máquinas de vapor, las hilanderas mecánicas y el ferrocarril. La orquesta creció imparable, el piano duplicó en potencia y posibilidades a sus predecesores, el metrónomo y la pianola se universalizaron, y las composiciones cultas desarrollaron unos rasgos y complejidad impensables anteriormente. Asimismo, la voz humana se ahogó temporalmente bajo la avalancha instrumental.

Palabras clave: afinidad sónica, siglo XIX, revolución industrial, paisajes sonoros, romanticismo

\section{Mimesis sonora e metamorfose estética: o século XIX como uma etapa crítica na história do pensamento musical}

\section{Resumo}

A teoria da afinidade sônica (Campos, 2016) considera que o cérebro musical humano é modelado pela ação dos sons recebidos desde a formação do ouvido, gerando perfis sonoros e estéticos em processos miméticos integrados 
na lógica evolutiva. Aplicada ao campo da musicologia histórica, permite analisar o século XIX como uma etapa determinante de mutações musicais após a revolução industrial, que aniquilou a quietude sonora do Antigo Regime com o estrépito dos motores a vapor, fiandeiras mecânicas e ferrovias. A orquestra cresceu imparável, o piano dobrou em poder e possibilidades os seus antecessores, o metrônomo e a pianola se tornaram universais, e as composições eruditas desenvolveram características e atingiram níveis de complexidade anteriormente impensáveis. Da mesma forma, a voz humana se afogou temporariamente sob a avalanche instrumental.

Palavras-chave: afinidade sônica, século 19, revolução industrial, paisagens sonoras, romantismo

\title{
Sound Mimesis and Aesthetic Metamorphosis: The $19^{\text {th }}$ Century as a Critical Stage in the History of Musical Thought
}

\begin{abstract}
The theory of sonic affinity (Campos, 2016) considers that the human musical brain is modeled by the action of sounds received since ear formation, generating sound and aesthetic profiles in mimetic processes integrated in the evolutionary logic. Applied to the field of historical musicology, it allows analyzing the $19^{\text {th }}$ century as a determining stage of musical mutations following the industrial revolution, which smashed the sound stillness of the Ancient Regime with the noise of steam engines, mechanical spinners and the railroad. The orchestra grew unstoppable, the piano doubled its predecessors in power and possibilities, the metronome and the pianola became universal, and cultured compositions developed previously unthinkable features and complexity. Likewise, the human voice drowned temporarily under the instrumental avalanche.
\end{abstract}

Keywords: Sonic affinity, $19^{\text {th }}$ century, industrial revolution, soundscapes, romanticism

\section{Introducción: la teoría de la afinidad sónica y sus aplicaciones}

En base a la teoría de la afinidad sónica, este estudio interpreta el siglo XIX como una fase crucial de transformaciones en el paisaje sonoro de las entonces modernas ciudades, y consecuencias musicales correlativas. La teoría de la afinidad sónica (Campos, 2016 y 2018; Campos y Cea, 2019) 
considera que el cerebro musical humano está modelado por la acción de sonidos recibidos desde la primera formación del oído (incluyendo la fase prenatal), generando perfiles sonoros y patrones de preferencia estética en procesos miméticos que se insertan dentro de la lógica evolutiva de adaptación y supervivencia. A la hipótesis descrita, el trabajo inicial de Campos (2016) añadía una triple fenomenología causal explicativa, que localizaría la razón de ser de esta respuesta espontánea del ser humano (perfectamente visible desde la primera infancia) en los principios de la capacidad de ataque y defensa, del fundamental acceso a la comunicación (especialmente en el aprendizaje instintivo del lenguaje oral), y de la no menos esencial necesidad de orientación del 'yo' -frente a uno mismo y frente al mundo circundante-. La afinidad sónica se formula mediante un esquema de análisis flexible que permite su proyección sobre diferentes campos disciplinares, de forma complementaria y en ningún caso excluyente (figura 1 ).

No disponemos de espacio para desarrollar en detalle la teoría en sí misma ni los distintos elementos visibles en este esquema, sino que vamos a enfocar la cultura aural de un periodo muy concreto. ${ }^{1}$ Aplicado al campo de la musicología histórica, el principio de la afinidad sónica puede aplicarse al siglo XIX en tanto que fase de mutaciones musicales determinantes a raíz de la explosión sonora derivada de la revolución industrial, que proscribió para siempre la quietud sonora del Antiguo Régimen con el estruendo de las máquinas de vapor, las hilanderas mecánicas, los telares industriales y el ferrocarril. Así, las notorias diferencias estéticas entre Vivaldi o Handel respecto de Bruckner o Mahler no se restringirían exclusivamente a cuestiones de evolución natural y temperamento individual, sino que obedecerían también largamente al heteróclito entorno sensorial-auditivo de su tiempo. La orquesta creció imparable, el piano duplicó en tamaño, potencia y posibilidades a sus

\footnotetext{
${ }^{1}$ Por tanto no repetiremos aquí el extenso aparato teorético y fundamentación empírica desarrollados en los trabajos citados sobre la afinidad sónica. El artículo de 2016 contiene básicamente la formulación de la teoría, un recorrido en profundidad de contribuciones complementarias, y una bibliografía especializada (Campos, 2016). El trabajo publicado en 2018 es una aproximación holística a la aplicación de la afinidad sónica a los principales géneros musicales (Campos, 2018). El artículo en colaboración (Campos y Cea, 2019) es un estudio empírico destinado a validar o refutar tres hipótesis asociativas entre paisajes sonoros de la infancia y preferencias musicales ulteriores (uso intensivo de aparatos digitales con el tecno; exposición regular a la televisión con el rap; y vivir en ambientes ruidosos con el heavy). Recientemente hemos accedido a un concepto que posee un contenido acaso complementario: el de paisagem cantada (paisaje cantado), que Duarte establece como forma de identidad sonora de quienes integran "uma mesma comunidade empática e acústica" (2015, p. 25). Duarte señala que "[n]a música raiz a poética-narrativa atua como forma de evocação de um universo histórico, espacial e sónico associado ao modo de vida rural do centro-sudeste brasileiro" (2015, p. 10).
} 
predecesores, ingenios mecánicos como el metrónomo y la pianola se universalizaron, y las composiciones cultas alcanzaron una complejidad y rasgos formales impensables anteriormente. Asimismo, la voz humana sucumbió temporalmente bajo los efectos de la avalancha instrumental -al igual que en las fábricas no era posible escucharse ni gritando, debido al estruendo de las máquinas (Smith, 2012)- lo cual condujo a un estadio casi anómalo dentro de la historia de la música, ya que el canto había sido desde el origen de la humanidad la forma primordial de hacer música.

\begin{tabular}{|c|c|c|c|c|c|c|c|c|c|}
\hline \multicolumn{5}{|c|}{$\begin{array}{l}\text { Proyección académica } \\
\text { Ontologia del fenómeno sonoro y la música }\end{array}$} & Arte sonoro & \multicolumn{2}{|c|}{ Proyección social } & \multicolumn{2}{|c|}{ Ambito individual } \\
\hline \multicolumn{4}{|c|}{$\begin{array}{c}\text { Musicologia } \\
\text { La teoria de los afectos y la re-interpretación del 'contexto' }\end{array}$} & Estudios de sonido & $\begin{array}{c}\text { Estéticas } \\
\text { experimentales }\end{array}$ & Educación & $\begin{array}{l}\text { Diseño urbano } \\
\text { y ecologia. } \\
\text { Arquitectura }\end{array}$ & $\begin{array}{l}\text { Auto-orientación, } \\
\text { identidad y } \\
\text { carácter personal }\end{array}$ & $\begin{array}{l}\text { Terapias } \\
\text { musicales }\end{array}$ \\
\hline $\begin{array}{c}\text { Afinidad } \\
\text { sónica basal. } \\
\text { Musicologia } \\
\text { sistemática }\end{array}$ & $\begin{array}{c}\text { Musicologia } \\
\text { histórica: } \\
\text { composición y } \\
\text { teoria de la } \\
\text { música }\end{array}$ & Etnomusicologia & $\begin{array}{l}\text { Estudios } \\
\text { de música } \\
\text { popular }\end{array}$ & Transdisciplina & $\begin{array}{l}\text { Vanguardias } \\
\text { musicales }\end{array}$ & $\begin{array}{l}\text { Formación } \\
\text { civica }\end{array}$ & $\begin{array}{c}\text { Espacios } \\
\text { compartidos. } \\
\text { Celebraciones } \\
\text { sonoras }\end{array}$ & $\begin{array}{l}\text { Espacios } \\
\text { afectivos. } \\
\text { Preferencias } \\
\text { musicales }\end{array}$ & $\begin{array}{l}\text { Aplicaciones } \\
\text { psicológicas }\end{array}$ \\
\hline $\begin{array}{l}\text { Origen y } \\
\text { naturaleza de } \\
\text { la música }\end{array}$ & $\begin{array}{l}\text { Historia del } \\
\text { sonido }\end{array}$ & $\begin{array}{l}\text { Culturas } \\
\text { sonocéntricas }\end{array}$ & $\begin{array}{l}\text { Estudios } \\
\text { culturales }\end{array}$ & $\begin{array}{l}\text { Antropologia social, } \\
\text { sociologia, neurologia, } \\
\text { musicologia, } \\
\text { psico-acustica, } \\
\text { percepción del sonido. } \\
\text { estudios cognitivos }\end{array}$ & $\begin{array}{l}\text { Composición } \\
\text { convencional }\end{array}$ & $\begin{array}{r}\text { Tecnologí } \\
\text { con lo } \\
\text { Nuevos } \\
\text { sociales } \\
\text { co }\end{array}$ & $\begin{array}{l}\text { e interacción } \\
\text { s medios. } \\
\text { significados } \\
\text { conciencia } \\
\text { ectiva }\end{array}$ & Bienestar y realiz & ción personal \\
\hline $\begin{array}{l}\text { Mecanismos } \\
\text { adaptativos: } \\
\text { evolución y } \\
\text { supervivencia }\end{array}$ & $\begin{array}{l}\text { Condicionante } \\
\text { estético }\end{array}$ & $\begin{array}{l}\text { Reinterpretación } \\
\text { de instrumentos } \\
\text { y danzas }\end{array}$ & $\begin{array}{l}\text { Fenómeno } \\
\text { actual }\end{array}$ & $\begin{array}{l}\text { Lenguajes tonales; } \\
\text { taxonomias } \\
\text { lingüisticas }\end{array}$ & $\begin{array}{l}\text { Combinación } \\
\text { multi-sensorial }\end{array}$ & Nuevas & culturas audi & $s$ (individuales $+c$ & lectivas) \\
\hline
\end{tabular}

Figura 1. Proyecciones y ámbitos de aplicación de la teoría de la afinidad sónica. ${ }^{2}$

Hay historiadores de la música "contextualistas” (en sentido sociológico) que comprenden instintivamente la necesidad de ensanchar el mero análisis de la composición -entendida como sujeto ontológico aislado- con la aportación de perspectivas y disciplinas que tengan en cuenta el marco referencial de realización. Pero un estudio renovador puede sobrepasar la conocida combinación de "obra + contexto"; es dentro de esta óptica de exigencia científica, que busca razones alternativas más allá del dualismo descrito que rige la musicología convencional, donde mejor se inscribe y comprende la aportación de una teoría como la de la afinidad sónica:

Even the formula 'compositional and contextual', suggestive of a dual perspective -a 'double root'- may not fully embrace the materials and

\footnotetext{
${ }^{2}$ Este esquema, en lectura horizontal, presenta en las columnas de la izquierda los bloques de proyección académica de la teoría de la afinidad sónica, subdivididos entre "Musicología” y "Estudios de sonido". La columna central ("Arte sonoro") esquematiza asociaciones posibles entre determinados paisajes sonoros y una recreación deliberada de contenido estético. Las columnas del bloque derecho sintetizan una serie de efectos secuenciales en base a la afinidad sónica, tanto sociales como individuales: en la planificación de espacios sonoros colectivos, y por la repercusión en la vida privada de los individuos. Del conjunto emergen cíclicamente nuevas culturas sonoras.
} 
methods of a music history [...] Texts, sounds, activities: all are primary data [...] If we want to write history we need to fill the spaces between works, to find strategies for connecting them (Samson, 2001, p. 3).

Samson acierta al detectar espacios vacíos que rellenar entre los sujetos inmanentes de la música, que son las composiciones, y el nivel estésico en que tiene lugar su recepción. Con ese propósito vamos a contemplar en primer lugar la monumental eclosión sónica que tuvo lugar con el advenimiento de la revolución industrial, y que atraviesa de parte a parte el siglo XIX. En segundo lugar veremos cómo hubo una réplica gradual y compleja en la producción musical coetánea, tanto en términos de reflejo proporcional tendente al gigantismo, como de oposición e intimismo. Los instrumentos musicales, la orquesta y la voz humana fueron partícipes fundamentales en el proceso. Finalmente examinaremos algunas composiciones específicas, partituras incluidas, que evidencian la densidad y trascendencia del giro acústico, histórico y estético en los distintos parámetros formales del hecho sonoro.

\section{El siglo XIX en la historia del sonido}

En cuanto al siglo XIX, ciertamente es un "lugar en la historia" -en la conocida metáfora-con sus correspondientes estereotipos y distorsiones. Para el presente estudio, el periodo a considerar se ha establecido en función del criterio de la sonoridad, abarcando desde finales del siglo XVIII -Revolución francesa, inicio de la revolución industrial y fin del Antiguo Régimen- hasta aproximadamente la primera guerra mundial. A escala tecnológica hubo un desarrollo sin precedentes, que hizo posible el advenimiento de novedades musicales críticas, como los nuevos instrumentos musicales, la creación de orquestas estables, y la fabricación del metrónomo. A escala sociológico-sensorial, todo apunta a que el oído musical de la audiencia demandaba tales cambios.

¿Cómo "sonaba" el siglo XIX? es la pregunta obligada para comenzar. Pese a que la grabación sonora no llega hasta 1878 (con el fonógrafo y los cilindros de cera de Edison), el cine hasta 1895, y radio y TV algo más tarde, del siglo XIX nos separa relativamente poco tiempo, y han sobrevivido innumerables testimonios escritos, iconográficos y por legado oral; por ejemplo, la prensa periódica era un medio plenamente asentado a mediados de siglo en muchos países. En materia de sonido la coincidencia de fuentes es aplastante: los ciudadanos que vivieron la primera oleada industrial la experimentaron como una verdadera revolución 'sonora', por encima de cualquier otra apreciación, y temible en ese sentido. Las nuevas máquinas eran sumamente toscas y con bajo aprovechamiento de la 
energía que consumían; por ello los niveles de desprendimiento en calor y estrépito resultaban insufribles para quienes habían vivido desde siempre en espacios sonoros caracterizados por la moderación y la discontinuidad. La máquina introdujo sonoridades de bajo contenido informativo, pero gran potencia y, especialmente, regularidad al no interrumpirse su funcionamiento durante largos períodos de tiempo. En conjunto el siglo XIX fue un momento crucial en la historia del sonido y de su percepción:

[0]f all of the principal developments usually associated with the coming of modernity in the nineteenth century, industrialization was understood, especially by contemporaries but also by some historians, as very much an aural affair (Smith, 2012, p. 40).

Veamos algunas muestras. En Das Eisenwalzwerk (El molino de hierro, 1875. Figura 2) Adolf Menzel utilizó en el título la metáfora del viejo oficio de molinero para la masificada y estruendosa fábrica. En efecto, en muchos lugares se pasó del pequeño taller (frecuentemente integrado en la vivienda del maestro) a la gran fábrica en el extrarradio, con cientos de obreros, producción en cadena, polución incontrolada, y niveles de ruido desmedidos. Y es que la moderna fábrica fue también una fábrica de ruidos. Si ahora tendemos un primer puente hacia la música culta en términos de paralelismo, comprobaremos que en muchas composiciones del siglo XIX la orquesta es inmensa en comparación con cualquier etapa anterior, con pasajes llamativamente enérgicos y pesantes.

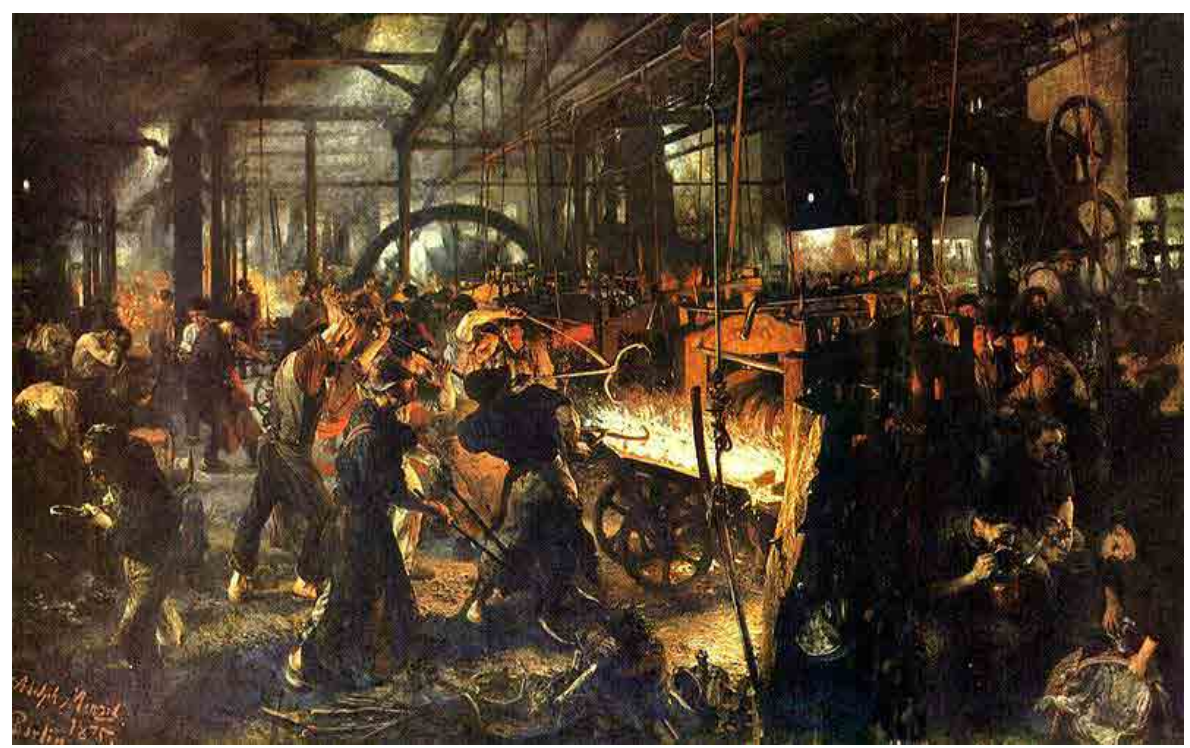

Figura 2. Menzel: Das Eisenwalzwerk (1875). Museo Estatal de Berlín. 
Sin embargo el principal invento de la primera oleada industrial fue el ferrocarril. ${ }^{3}$ Las locomotoras de vapor invadieron progresivamente la apacible campiña europea, sembrando el pánico entre los lugareños. Las locomotoras rugían y arrojaban masas de ceniza incandescente, el convoy crujía en los cambios de vía, y los atropellos eran frecuentes. El ruido de las locomotoras de vapor era escandaloso, aterraba a personas y animales, unido a la intensa humareda y aspecto amenazador. Charles Dickens protestó enérgicamente en la prensa (1855) por las molestias que ocasionaba el ferrocarril en su barrio londinense de Stagg's Gardens, preguntando:

What changed our neighbourhood altogether and for ever? [...] what put the neighbourhood off its head, and wrought it to that feverish pitch that it has ever since been unable to settle down to any one thing, and will never settle down again? THE RAILROAD has done it all. (Mayúsculas originales; citado en Trower, 2012, p. 121).

Otro conocido escritor, Lawrence Durrell, relataba un viaje en un vetusto tren yugoeslavo a principios del siglo XX:

No es que fuera estridente, no. Quitaba la respiración. [...] El estruendo era tal que no podíamos hablar, teníamos que gritar [...] [C]ada quinientos metros gemía y arrojaba a la noche andanadas de blancas pavesas que abrasaban la hierba a ambos lados de las vías. Desde lejos debíamos de parecer el incendio de un bosque avanzando. [...] [N]os mirábamos con desesperación entre la baraúnda infernal y nos sobresaltábamos a cada tumbo [...] (Durrell, 2017, pp. 14-16).

Lawson y Stowell señalan al siglo XIX como "the age of mechanization and the railway" (2004, p. 83). Las calles de las principales ciudades pasaron de ser simplemente bulliciosas a estrepitosas; en la Inglaterra victoriana: "[i]n 1864 the first Bill passed through Westminster for the control of street noise" (Trower, 2012, p. 110). Picker apunta que se trató de un periodo de "unprecedented amplification, unheard-of loudness" (2003, p. 4). Por añadidura:

Benjamin Wooley writes that the effects of industrialization and mechanization were felt across all levels of society, each new development feeding another in a chain reaction that shook the

\footnotetext{
${ }^{3}$ En 1840 había en toda Europa 3.000 km de ferrocarril, con un total de 2'5 millones de viajeros/ año entre Francia, Inglaterra y Alemania. En 1891 había 218.000 km de ferrocarril europeos, y 614 millones de viajeros/año entre esos tres países (Trower, 2012, p. 107).
} 
world, and shakes it still'. [...] Nordau's Degeneration [...] describes the changes taking place as a kind of earthquake, in this case to emphasize the destructiveness of such dramatic transformation [...] The classic work of Karl Marx and Friedrich Engels [The Communist Manifesto, 1882] also uses the rhetoric of earthquakes to convey how change is not simply progressive (Trower, 2012, p. 120).

Ya en 1819 el joven Mendelssohn, extranjero en Londres, estaba aturdido por el fragor de la capital inglesa, y escribía por carta a su familia:

It is fearful! It is maddening! I am quite giddy and confused. London is the grandest and most complicated monster on the face of the earth. [...] Things roll and whirl round me and carry me along as in a vortex (citado en Davies y Lockhart, 2017, p. 7).

En efecto, se rompía irreversiblemente la paz sonora del Antiguo Régimen, y no sólo en el ámbito europeo. Los habitantes finiseculares de Nueva York sufrían un "continual rattle, roar, and screams [...] nearly all hours of the day and night [...] [in a] ceaseless assault of confused and discordant noises" (Girdner, 1896, pp. 297-298). En conjunto hubo una estrecha fusión entre ciencia y música que desembocó en un mar de sonoridades nuevas y consiguiente adaptación del oído del oyente, que acusó "the enormous expansion of the sense for sound" que acontecía a mediados del siglo XIX, a partir de la "extraordinary acceleration of musical activity and scientific innovation" (Davies y Lockhart, 2017, p. 2). La época dejó artilugios singulares por el tamaño y potencia sonora; tal fue el caso de la Daboll trumpet, construida en torno a 1890 en Boston como faro acústico para los barcos en días de niebla (figura 3). ${ }^{4}$

\footnotetext{
${ }^{4}$ Es obvio que estas concatenaciones, que aquí estimamos en términos de causalidad, no se limitan a una centuria; en el caso de las ciudades americanas, la conexión entre el estrépito urbano y el jazz resultaba evidente para sus propios habitantes al inicio del siglo XX (Campos 2016). La afinidad sónica aplicada a géneros de música popular y culturas preindustriales puede verse en otros trabajos de J. Campos citados.
} 


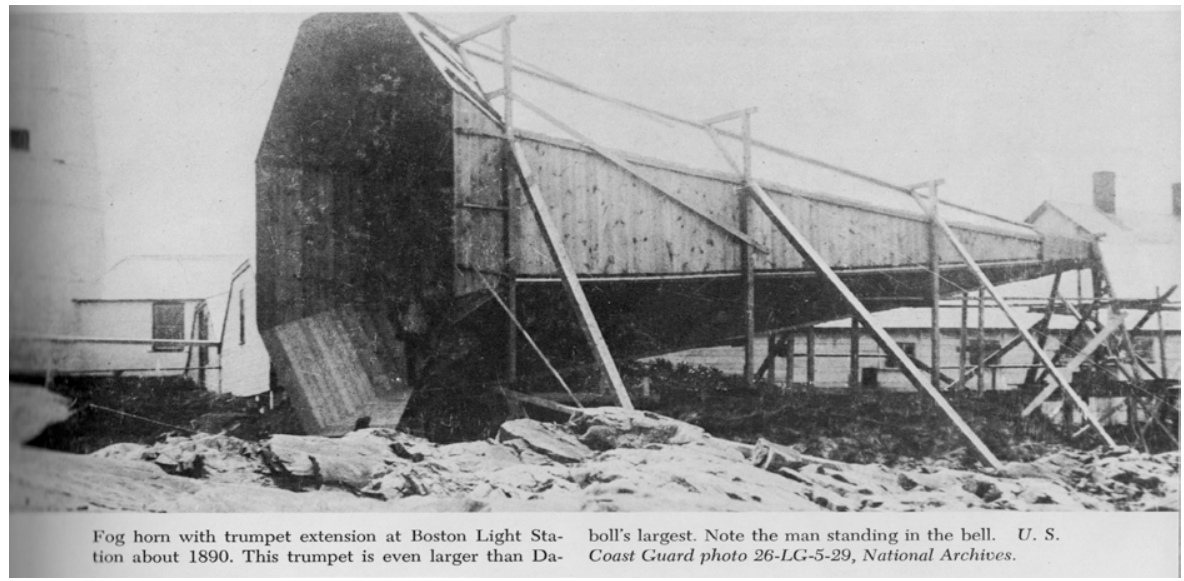

Figura 3. Daboll trumpet. Boston, ca. $1890 .^{5}$ Obsérvese la figura humana en el cono de salida.

La musicología despegó entonces con fuerza, lo que no es una casualidad si se tiene en cuenta la formidable simbiosis entre música y avances científicos que estaba teniendo lugar. En Londres y otras metrópolis desarrolladas se empezaron a fundar instituciones musicológicas, se publicaron revistas especializadas, se crearon conservatorios, auditorios, orquestas y coros estables, y se generalizó el concierto público, ante audiencias regularmente masivas. Paralelamente, el afán por el progreso y la fe en que su crecimiento infinito sería la solución de los problemas de la humanidad llevó a eliminar todo obstáculo al avance industrial, generando culturas aurales completamente nuevas en la historia. Gawthrop estima que: "[t]he Industrial Revolution produced a shift from the rural to the urban. The noise of machinery and the cacophony of the streets filled all waking hours" (2012, p. 166). Se trató de un cambio más profundo que la mera elevación de los niveles sonoros; Leo Marx en The Machine in the Garden (1964), entendía el chirrido de la locomotora como una ruptura real y simbólica del ideal pastoral. Para Marx, el icono rural funcionaba cada vez más como un escape de los estragos -incluido el acústico- ocasionados por la modernidad. Ese anhelo bucólico sin duda estuvo en el arranque del pensamiento estético romántico, que haría de la naturaleza un ideal absoluto en peligro de extinción. Pero incluso en un motivo tan universal como el del pastoralismo se iba a evidenciar la profunda transición experimentada:

Deployment of the pastoral style in, for example, the "Pifa" from Part I of Handel's Messiah and Liszt's Les préludes might indicate superficial stylistic affinities (compound meter, major modality, drone bass), but these qualities have to be understood against the backdrop of sharply

${ }^{5}$ Imagen en Hecker (2014, p. 118). 
contrasted social contexts: the "other" of Liszt's pastoral music is an industrialized urban landscape that Handel could scarcely have imagined (Horton, 2014, p. 643).

\section{La réplica musical: afinidad y gigantismo}

La música culta absorbió espontáneamente y en términos de afinidad el nuevo universo sonoro que invadía todo, plasmándolo en obras y prácticas interpretativas específicas. Rossini, Verdi, Wagner, Bruckner, y muchos otros compositores "románticos" (dentro de lo imprecisa y discutible que es esta etiqueta) articularon musicalmente el gigantismo y la continuidad de los entonces nuevos paisajes sonoros, a través de un paralelismo musical patente en muchos casos. En el ámbito de los conciertos públicos la noción de un espacio aural masivo y compartido, pronto tuvo ecos tangibles que sobrepasan los criterios explicativos de lo demográfico y lo tecnológico (figura 4). Como señala Hecker: "[t]he power of loud sound was appealing for many reasons, be it narcotic, communicative, or musical" (2014, p. 12). El siglo XIX fue un tiempo histórico esencialmente sonoro, en términos de inusitada amplificación tanto en lo relativo a la intensidad de la obra como de la masiva concurrencia de intérpretes y público, "a culture of musical immensity" (2014, p. 54).

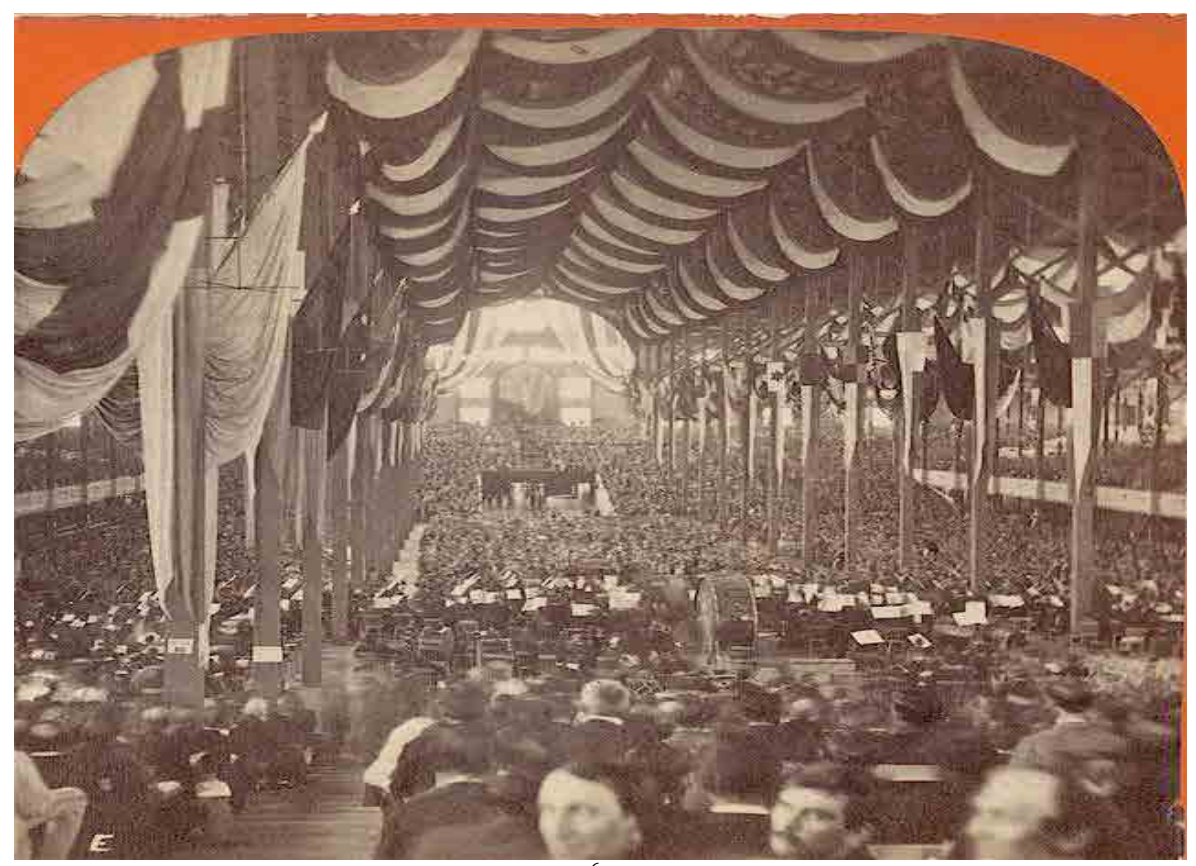

Figura 4. Fiesta de la Paz Nacional, Boston, $1869 .^{6}$

${ }^{6}$ Imagen en Hecker (2014, p. 10). Obsérvese el carácter multitudinario por igual de intérpretes y 
No faltan datos objetivos: por ejemplo, un local muy popular, que de alguna forma reflejó el triunfo de la masividad sonora y humana en el Londres del cambio industrial, fue sin duda el Exeter Hall, terminado en 1831, "to host crowds of thousands" (Davies y Lockhart, 2017, p. 16). En su autobiografía (1865) Louis Spohr lo describía así:

Imagine a gigantic hall with places for 3,000 persons, crammed full, head above head [with a] magnificent and stupendous organ, and on all sides around it, an orchestra and choir of singers number 500 persons (citado en Davies y Lockhart, 2017, p. 17).

En esta nueva esfera relacional entre obra y audiencia, sobre la mera atracción de la novedad y la espectacularidad se podían superponer connotaciones de orden moral y político: "Exeter Hall was conceived as the moral center of empire, bringing together the voices of creation and gathering news" (Davies y Lockhart, 2017, p. 17). En la Exposición Universal de París (1889), para la que se construyó la Torre Eiffel entre otras empresas de gigantismo y monumentalidad urbana, la música fue omnipresente, una verdadera orgía musical (Fauser, 2005), convirtiéndose así en un significante acústico de la especificidad del evento:

Music was so pervasive and inescapable that, as we read in a report from May 1889, it was perceived as being "everywhere, raging with equal violence at the bandstand of the gypsies, under the tents of the Arabs, in the picturesque shacks of Morocco and Egypt" (p. 7).

Ello propició una simbiosis celebratoria entre localidad y paisaje sonoro; el recinto ferial pasó a ser un microcosmos cultural que reflejaba fielmente el mundo exterior allí comprimido, como un laboratorio tanto de percepción aural como de usos musicales en la Francia decimonónica, en aquella su gran feria de exaltación de la identidad nacional. Como afirma Fauser (2005), el espacio circundante moldeaba la escucha:

[I]ndeed, the politics of sound became tangible in presentation and reception within the townscape of the fair. [...] Music's physical location within the fair became one form in which the sound politic could be

público. Al margen de la concatenación acústico-social, estos eventos representaron la democratización del hecho musical, tocando en un espacio abierto para miles de personas. En la narración de Hecker: “In 1869, a very large musical celebration took place in Boston, Massachusetts. The National Peace Jubilee, as it was called, was a gathering of some 11,000 singers from some 100 choral groups with over a thousand-piece orchestra section. It was then proclaimed to be the "greatest musical enterprise of modern times."' $(2014$, p. 8). 
seen embodied, not only with respect to the place as such, but also in the way in which listening modes were shaped through location. Townscape and soundscape were inextricably intertwined (p. 9).

La orquesta merece un comentario aparte: en el siglo XIX creció hasta desbordar por completo la sencilla agrupación de cuerda con el añadido de uno o dos aerófonos y continuo, que había sido la formación habitual en la música clásica desde el barroco temprano.

After mid-[nineteenth] century the orchestra came to include additional wind timbres such as cor anglais and bass clarinet [...] Instruments were invented in large numbers [...] Improvements were often focused towards achieving greater power and (in the case of woodwinds) acquiring greater flexibility in remote keys (Lawson y Stowell, 2004, p. 98).

Es interesante que la sección de viento-metal (la más potente del grupo) y la de percusión fueron las que más se desarrollaron proporcionalmente. El 'metal' era además vistoso por el bronce utilizado, y aunque de un lujo ajeno a la maquinaria de trabajo, concordaba como materia prima metalúrgica con el hierro y acero que se emplearon masivamente en las fábricas. El viento metal fascinó al mundo musical coetáneo, más allá de lo que la pura lógica de la evolución estilística puede explicar. Estos instrumentos llevaron la voz de las fábricas a la sala de conciertos (figura 5).

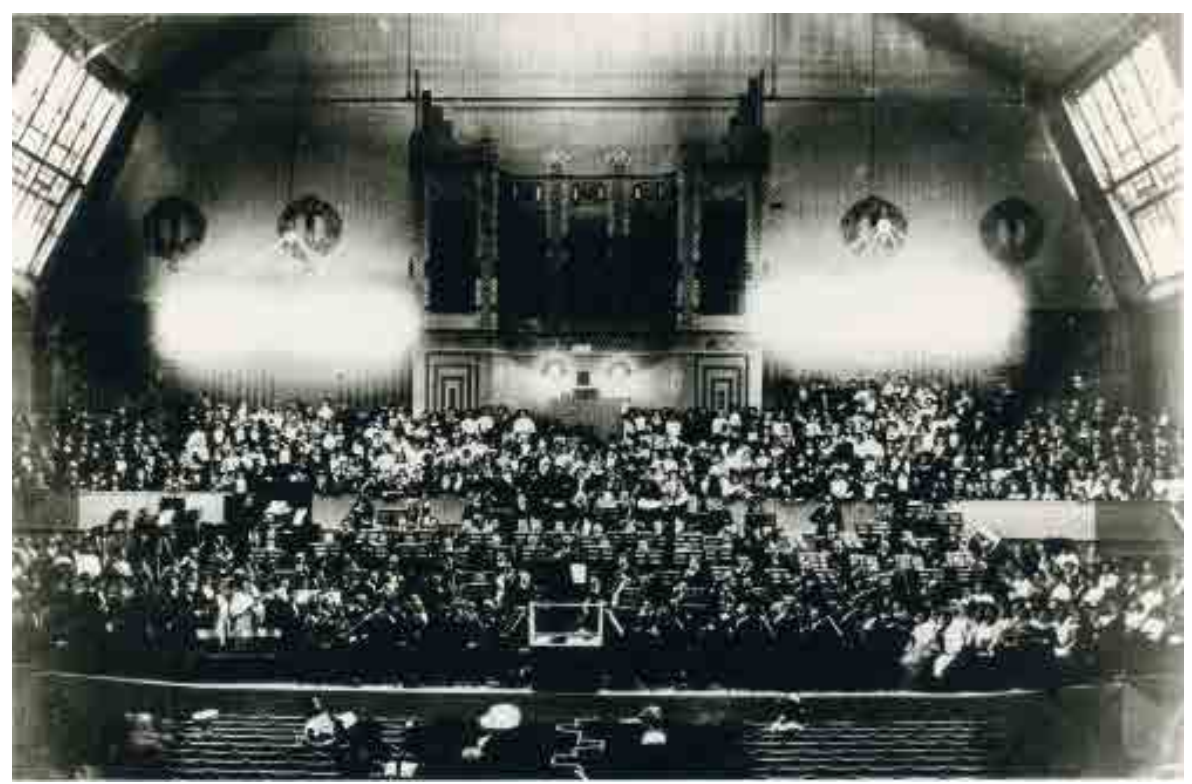

Figura 5. Gigantismo musical. Mahler ensayando para el estreno de su octava sinfonía. Munich, 1910. La obra fue apodada 'sinfonía de los mil' por el elevado número de intérpretes que requiere.

${ }^{7}$ Imagen: Gustav-Mahler.eu Recuperado de https://www.gustav-mahler.eu/index.php/plaatsen 
Como estamos comprobando, los instrumentos pasaron a primer plano en la música del siglo XIX. Se inventaron la tuba wagneriana, el saxofón y el acordeón (ingenios que reflejaron la potencia y estridencia de su tiempo), pero entre todos iba a destacar el piano, que se impondría netamente en el competido territorio de solistas y virtuosos, sobrepasando al violinista y al castrato que habían dominado el siglo anterior. Tras unos orígenes dieciochescos discretos pasó a ser el rey de los instrumentos y titán de la música. El piano duplicó en tamaño, potencia y posibilidades a sus predecesores, y la figura del pianista se erigió en divo por excelencia del escenario musical. El célebre crítico E. Hanslick describía en la $2^{\underline{a}}$ mitad del siglo XIX el giro operado:

In Mozart's and Haydn's day the piano was a weak, thin box with a soft tone, scarcely audible as far as the front room [...] The full tone and carrying power of the modern piano arise from its great size, its colossal weight and the tensions of its metal trengthened frame [...] The instrument has gained this offensive power and offensive character for the first time in our day (citado en Schafer, 1994, p. 109).

El piano sobrepasó los parámetros de la innovación morfológica, accediendo a un estadio semántico referencial:

Not only did the [piano] generate a new repertory, where style and medium are locked together by an idiomatic imperative. It also transformed the social history of music; the instrument itself became a social agent (Samson, 2001, p. 6).

El moderno piano supuso la culminación de una ingeniería organológica muy avanzada, fiel espejo de su tiempo, capaz de desplegar una gran potencia acústica y variedad polifónica, ejecutar todos los matices dinámicos, y subyugar a la audiencia con el virtuosismo vertiginoso del intérprete. Además era un instrumento de 'percusión', y los pasajes repletos de energía, ritmo trepidante y heroísmo apasionado de Beethoven, Chopin y Schumann, entre otros, encajaban a la perfección con el mundo sonoro coetáneo. Los marcados contrastes dinámicos, intercalando frases de extremado lirismo, acentuaban la tensión expresiva y hacían aún más vigorosa la reaparición del fortissimo. Las piezas sentimentales de sonido tenue y doliente se hicieron igualmente populares en el salón romántico, dando cauce al anhelo nostálgico de muchos aficionados a la música que añoraban el tiempo pasado de paz y quietud anteriores 
al estruendo de la máquina y destrucción del medio natural. De ahí que la música llegase a ser la primera entre todas las artes en el siglo XIX, porque fue una centuria de cambios determinantes en el ámbito auditivo, con amplio impacto sociocultural.

El XIX fue también el siglo de ingenios sonoros mecánicos como la pianola, el diapasón, el metrónomo y la sirena, que pronto se universalizaron. Jackson detecta en las primeras décadas una creciente "mechanical tyranny of precisión" (2012, p. 210). El pasional e improvisador Beethoven vio grandes ventajas en un aparato tan inhumano y "tiránico" como el metrónomo:

Maelzel's metronome gives us an excellent opportunity to do so [i.e., ensure that the composer's intentions were followed]. I give you my word for it here, in my further compositions I shall not use those terms [tempi indications]. [...] That one will cry out "tyrants", I do not doubt [...] [Beethoven, citado por Jackson 2012, p. 212. Cf. Brown, 2009).

Y así lo hizo: a partir de su sonata op. 106 en Si bemol mayor, Hammerklavier (1818), Beethoven añadió indicación metronómica a todos los movimientos de sus sinfonías. ${ }^{8}$

Un teclado mecánico comparable a la pianola fue la celestina, patentada por el inventor inglés Adam Walker en 1772: "a harpsichord equipped with a mechanism for bowing the strings" (Loughridge, 2017, p. 47). Fue precedida por el lyrichord de Roger Plenius en 1741 (2017, p. 58). En las calles más céntricas de las grandes urbes había saturación de barrel organs (organillos) en las primeras décadas del s. XIX, instrumento a fin de cuentas tan maquinal (en el sentido aquí desarrollado) como los anteriores.

La esfera militar absorbió plenamente las transformaciones que acarreaba la era industrial y la mecanización del trabajo, así como tuvo que enfrentarse a las exigencias derivadas de las guerras napoleónicas, el despertar de los modernos nacionalismos y las subsiguientes revoluciones burguesas que marcan el final del siglo XVIII y primeras décadas del XIX. En su estudio de la música en el centro militar de Woolwich (sureste de Londres), Werrett destaca "the rise of military music in the

\footnotetext{
${ }^{8}$ Esta sonata es una de las obras técnicamente más exigentes del repertorio pianístico universal, y su título (Große Sonate für das Hammerklavier), aunque no pretendía en modo alguno significar un "martillo" musical (como se ha dicho erróneamente muchas veces), sí se refería al pianoforte, es decir, al teclado percutivo que se estaba imponiendo sobre sus competidores de tecla.
} 
late eighteenth and early nineteenth centuries", y lo nivela con la cultura musical y transformaciones científicas de aquella etapa (2015, p. 87). Como consecuencia proliferó imparable la música militar: " $[\mathrm{t}]$ he military was probably the largest employer of European musicians in the first half of the nineteenth century" (2015, p. 88). El nuevo orden político y sonoro iba a determinar un modelo militar asimismo distinto; en la música castrense se impuso el canon marcial en elementos como el ritmo, la disciplina, la obligación de marcar estrictamente el paso, y la sincronía, que hacían del soldado una "human machine" (2015, p. 89). Se llegó a utilizar un péndulo para marcar el paso, exigiendo una precisión total y estableciendo en las marchas el número exacto de pasos y distancia a recorrer por minuto (siguiendo al péndulo). Como señala Werrett, "[t] he body had to defer to the machine" (2015, p. 91) en la pugna por una perfecta simbiosis entre máquina y persona, aunque con preferencia hacia la primera:

The ideal soldier should be a machine, moving to the beat of a drum regulated by a pendulum. Music played a role in regulating this machine and became an integral part of British regimental life (2015, p. 97). ${ }^{9}$

Este cúmulo de cambios y transiciones en la esfera laboral y cultural, en el ámbito público y en el privado, es visible en los países entonces más desarrollados, con ciertas singularidades. En Inglaterra hemos comprobado cómo el ferrocarril provocó un fuerte rechazo social por la contaminación acústica y ambiental que conllevaba. En Francia hay constancia del crecimiento del rumor cotidiano en el siglo XIX, sobre todo en París. La 'masa' orquestal y vocal que proponía Berlioz estaría representando a la masa humana y fragor callejero parisino: ${ }^{10}$

In his Grand Traité d'instrumentation, [Berlioz, 1844] describes his

\footnotetext{
${ }^{9}$ Desde finales del siglo XVIII, en Londres cobraron una notable actualidad los "music-playing autómata" (Davies y Lockhart, 2017, p. 6), diseños antropomórficos capaces de tocar algunas piezas. Entre otros ingenios y curiosidades de esta oleada de inventos acústicos, la firma Flight \& Robson creó "an immense mechanical orchestra [...] called the Apollonicon, installed at the Royal Cyclorama or Music Hall adjoining the Colosseum in Regent's Park from 1848” (2017, p. 6).

${ }^{10} \mathrm{~A}$ pesar de que en la dialéctica histórica Francia e Italia han sido siempre consideradas el reducto indomable de la ópera frente al sinfonismo germánico, el caso de Francia está sujeto a crítica (Cooper, 1983). Respecto de la música italiana, no hay duda de que se mantuvo fiel a una trayectoria secular; pero en el siglo XIX hay que valorar también su intenso proceso de unificación, en el que la música cantada desempeñó un papel especial, así como la rivalidad directa con el ámbito germano. En la batalla estético-política lo cierto es que a lo largo del siglo XIX Viena consolidó e incrementó su posición de capital de la cultura musical europea, en detrimento de las ciudades y músicos italianos.
} 
ideal orchestral and choral forces for Parisian festival occasions (467 players and 360 singers) [...] (Lawson y Stowell, 2004, p. 127).

En la célebre caricatura de Berlioz dirigiendo (figura 6), el viento-metal se torna un ejército ensordecedor, testimoniando la agresividad y gigantismo de la música culta decimonónica.

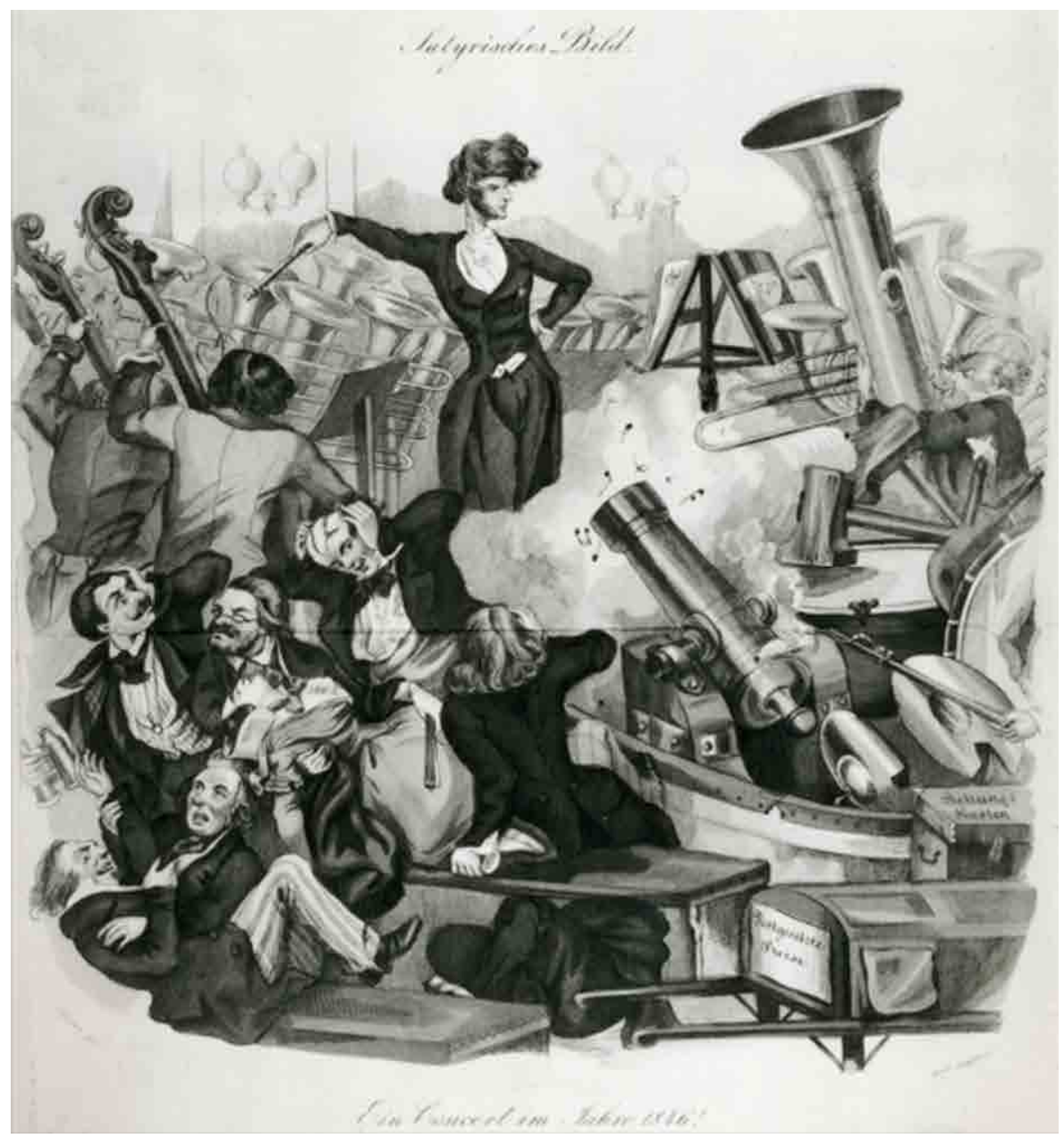

Figura 6. Andreas Geiger: Un concert à la mitraille au Théâtre de Vienne (1846). París, Museo de la ópera.

Una obra particularmente representativa de los cambios estéticos que Berlioz propugnaba fue su célebre Sinfonía Fantástica (1830, op. 14):

The symphony's novel soundscape was made possible by new instruments. Berlioz planned to include octabasses, oversized cellos [...] Berlioz also collaborated with Adolphe Sax, whose innovations included the saxophone, improvements on the proto-tuba ophicleide, and other brasses. These innovative instruments increased the range 
of the orchestra and added unprecedented musical "colors" [...] In the age of virtuoso performers like Paganini, Chopin, and Liszt [...] Berlioz presented himself as the virtuoso composer-conductor who played his orchestra like a kind of giant piano, appearing as an orchestra unto himself (Tresch, 2012, p. 141).

En otras obras Berlioz mostró la misma concepción gigantista e innovadora del timbre:

To obtain the maximum 'acoustic return', his Requiem included a giant chorus and twice the standard number of wind instruments. He also increased the strings, added ten tympanists, and set four groups of brass instruments in the corners of the performance space (originally a church), thereby "spatializing" the sound, so that "the fanfare seems to radiate out from the center of the orchestra" (Tresch, 2012, p. 142. El entrecomillado es texto de Berlioz).

Resulta interesante ese efecto acústico de distribuir la sección de vientometal (específicamente) en cuatro grupos en las esquinas para "espacializar" su sonido y que pareciera que emergía del centro de la orquesta; el viento-metal realmente se coronaba como dominador de la orquesta. A Berlioz también pertenecen una cantata en Si menor al ferrocarril ( $L e$ Chant des chemins de fer, 1846) y un Te Deum para más de mil intérpretes. En un momento determinado llegó a proponer utilizar un telégrafo eléctrico para coordinar la ejecución de los músicos (Tresch, 2012). Otros compositores practicaron un estilo espectacular (más que puramente masivo), como Meyerbeer, cuyas realizaciones constituían "a symphony of blaring saxophones, pounding tympani, or haunting masses of sound", que el público parisino recibía con estruendosos aplausos (Tresch, 2012, p. 304). París fue realmente una de las grandes capitales del progreso científico y tecnológico:

[W]ondrous new devices -electrical apparatus, geophysical instruments, daguerreotypes, musical instruments, stage sets, printing technologies, calendars, and the mother of them all, the steam engine- helped remake Paris in the first half of the nineteenth century (2012, p. 287).

Inmerso en el dinámico contexto sonoro de la capital francesa en la década de 1820, se comprende que Rossini pudiera concebir los contrastes y arrollador impulso rítmico de la obertura de Guillermo Tell y otras obras 
(ver más abajo). ${ }^{11}$ Era un tiempo de ruptura y experimentación, precursor de los futuristas italianos ${ }^{12}$ y el sound art contemporáneo, como en la ejecución que en 1845 el director y compositor francés afincado en Londres Louis Jullien llevo a cabo de su:

[...] first monster concert, with its 300-piece orchestra on a purposebuilt platform [...], and "Suoni la tromba" from Bellini's I Puritani scored for 100 mixed brass, ophicleide, and serpent (Davies y Lockhart, 2017, p. 9). ${ }^{13}$

Esta serie de testimonios y referencias, unida a los que siguen, refuerza la hipótesis central que rige el presente estudio, validando la noción de una conexión axial de afinidad entre espacios sonoros y producciones musicales, que en el siglo XIX adquiere un relieve particular por la acelerada y virulenta eclosión de los primeros.

En Alemania es fundamental el dato de cómo en el paso del siglo XVIII al XIX tuvo lugar: "the [...] sudden shift of instrumental music from the lowest to the highest of all musical forms, and indeed of all the arts in general" (Bonds, 1997, p. 387). También en esta faceta fue pionero Beethoven, cuyas obras vocales son inferiores en general a las instrumentales. Con Beethoven triunfó en particular el lenguaje sinfónico, como máxima expresión de la música absoluta, el ideal de belleza sonora y apoteosis de la exaltación romántica (Paddison, 2001). ${ }^{14}$ Géneros instrumentales conocidos y otros nuevos, como la sonata, la sinfonía, el concierto, el cuarteto, las variaciones y el poema sinfónico, crecieron en las preferencias compositivas y de la audiencia, sellando el triunfo del "aparato" sobre la "persona" como

\footnotetext{
${ }^{11}$ Sobre la evolución de la auralidad en el París moderno, se puede consultar Boutin (2015). Acerca de los años de Rossini en París es válido el volumen de Walton (2007), cuya portada utiliza un dibujo de Paul Delaroche titulado "Signor Tambourossini, ou la nouvelle mélodie" (1821), que es una muestra del pulso trepidante que el músico italiano imprimía a determinados pasajes instrumentales. El apelativo 'Tambourossini' es suficientemente expresivo, y en la caricatura Rossini figura en plena ejecución, pisoteando violines a golpe de bombo y trompeta mientras las ninfas huyen tapándose los oídos.

${ }^{12}$ De acuerdo con Hecker: "the Futurists were not necessarily singular avant-garde anomalies, but rather products of an era in which loud sound was a subject of broad concern" (2014, p. 21).

${ }^{13}$ En este trabajo omitimos, por no sobrecargar la documentación, instrumentos como la linterna de cristal, espectáculos como la fantasmagoría, y personajes como Gambara de Balzac, que sin duda anticiparon la técnica del cinematógrafo y determinadas narrativas del discurso estético del siglo XX.

${ }^{14}$ Con Beethoven se puede aventurar que nació la música bipolar, reflejo de un genio atormentado que transita desde el extremo más temperamental y explosivo a un intimismo lírico de máxima sensibilidad. Ello sucede en marcados contrastes dentro de una misma obra, sellando la dicotomía emocional característica del estilo romántico. Desde nuestro análisis esa acusada variabilidad debe una parte a la sonoridad de su tiempo (que Beethoven tuvo que percibir claramente pese a la sordera); la otra parte, y la más importante, es mérito exclusivo de su talento personal.
} 
voz. La máquina vencía al hombre, el hecho era incuestionable en múltiples facetas de la vida, y el ámbito del arte no fue ajeno. En efecto, la voz humana se ahogó temporalmente bajo la masa sonora instrumental, al igual que en las fábricas no era posible escucharse ni gritando, debido al estruendo de las máquinas (Smith, 2012). La teoría explicativa que a este respecto proponemos, en base al principio de la afinidad sónica, es que el notable incremento de los géneros instrumentales en el siglo XIX pudo tener relación con los sonidos dominantes de las máquinas, que imponían su potencia (atronadora), registro (grave) y regularidad (cíclica), sometiendo físicamente a los cantantes, cuyos parámetros acústicos no podían competir con los descritos. El hecho es que en el siglo XIX decaen las misas, los oratorios y las cantatas, desapareciendo virtualmente géneros ya obsoletos como el motete y el madrigal. La ópera se mantuvo vigente, pero con notables cambios estilísticos; por ejemplo en Wagner se habla de sinfonías vocales, por el carácter de tales que tenían sus óperas. ${ }^{15}$

El lied (pieza para voz solista acompañada de piano) será la expresión del salón romántico burgués, donde se hacía una música privada e intimista lejos del ruido callejero. El lied orquestal (voz solista acompañada de orquesta, un género plenamente decimonónico) acaso encarnó estéticamente esa soledad y cuasi indefensión de la voz humana frente a una masa instrumental que podría aplastarla en cualquier momento. Este rasgo se puede apreciar con claridad en el ciclo mahleriano La Canción de la Tierra (1909), donde con frecuencia la voz lleva la anotación de fortissimo y, por el contrario, los instrumentos son silenciados o intervienen con niveles bajos o medios de intensidad; únicamente las arpas (de sonido dulce) muestran ocasionalmente una notación sonora elevada; en ese sentido es notable la precisión de indicaciones dinámicas por parte de Mahler para mantener un cierto equilibrio entre las distintas partes. Estas obras evidencian el deseo de los compositores románticos y posrománticos de mantener el legado histórico de la voz humana en el discurso musical, pero entendiendo que alrededor hay un verdadero ejército de sonidos no humanos (como en las calles de entonces). Adicionalmente, La Canción de la tierra es un ciclo de seis lieder con forma de sinfonía, lo que corroboraría la noción de una instrumentalización de la voz en este período.

\footnotetext{
${ }^{15}$ La grand opéra francesa, los excesos corales de Berlioz, y algunos otros casos de macro-vocalidad en conciertos públicos, significaron de alguna forma la reacción en términos de gigantismo vocal al vocabulario musical del momento. El fenómeno del orfeonismo y auge de las sociedades corales, que se extiende imparable a lo largo del siglo XIX, tiene una fundamentación comparable desde el mismo punto de vista.
} 
Durante el largo siglo XIX se extingue progresivamente el estilo cantabile (vocal), que había dominado la música occidental desde la Edad Media hasta entonces, y las obras del romanticismo tardío se estructurarán conforme a principios menos "naturales" y más complejos. Sin embargo hay otra razón, sutil y no evidente, para comprender la progresiva liminalidad del canto: la propia fisicalidad de la voz como vehículo de palabras "materiales" y por tanto sujetas a un significado explícito. Los Lieder ohne Worte ("canciones sin palabras") de Mendelssohn, compuestos en 8 volúmenes entre 1829 y 1845 , pueden asumirse como la sustitución de la voz por el instrumento (piano). Son realmente lieder: la música "canta" en el piano como si fuera una voz humana, pero "sin palabras", es decir, sin emisión vocal. La lógica detrás de un ciclo así sólo puede comprenderse dentro del pensamiento estético del primer romanticismo alemán. En una carta de Mendelssohn a Marc-André Souchay en 1842 el músico se resistía a la literalidad explícita de la palabra:

People often complain that music is too ambiguous, that what they should think when they hear it is so unclear, whereas everyone understands words. With me, it is exactly the reverse, and not only with regard to an entire speech but also with individual words. These, too, seem to me so ambiguous, so vague, so easily misunderstood in comparison to genuine music, which fills the soul with a thousand things better than words. The thoughts which are expressed to me by music that I love are not too indefinite to be put into words, but on the contrary, too definite [...] (citado en Bonds, 2004, p. 193).

Con esas palabras Mendelssohn suscribía la supremacía de los instrumentos en la búsqueda de lo sublime, por ser aquéllos el medio supremo de expresión musical al hallarse desligados de las ataduras del lenguaje oral. Obsérvese la sutileza de que para Mendelssohn la música en estado puro es más concreta y precisa para expresar los sentimientos profundos que las "ambiguas" e "indefinidas" palabras.

\section{Una revolución acústica y estética}

A continuación desglosamos uno a uno los principales parámetros musicales en su profunda metamorfosis decimonónica. Prácticamente todos los espacios del hecho musical se vieron afectados por la revolución sonora que estaba teniendo lugar en la sociedad, y que iba a generar una cultura musical igualmente revolucionaria. Si exceptuamos al siglo XX, con sus vanguardias radicales, la introducción de los instrumentos electrónicos, 
la generalización de los sistemas de grabación y reproducción del sonido, y la explosión de la música popular urbana, sin duda alguna el siglo XIX ha sido el más transformativo del total de la historia de la música occidental.

En un curso impartido en 2004 en la UAM, el experto en ópera Roger Alier sostenía que el ritmo trepidante de las oberturas de Rossini se debía a la influencia inconsciente del ruido mecánico y reiterativo de las máquinas de hilar en los telares industriales. En efecto, el ritmo fue un parámetro directamente afectado por el universo sonoro industrial. Los primitivos telares, llenos de spinning machines, al parecer producían un ruido infernal; todo vibraba, hasta el suelo. Así lo confirma el testimonio personal de Lucy Larcom, una trabajadora de la fábrica textil Lowell en Massachusetts, en torno al año 1840:

In the sweet June weather I would lean far out of the window, and try not to hear the unceasing clash of sound inside. Looking away to the hills, my whole stifled being would cry out (Larcom, 1889, p. 182).

Con relación a la tesis de Alier, si se desea ver sintetizado en un contraste musical el tránsito de la Europa galante a la industrial, la Obertura de Guillermo Tell de Rossini es un ejemplo perfecto (figura 7). Incluso en el compás, que pasa del bucólico 3/8 lento, de marcadas resonancias pastorales, al marcial y mecánico $2 / 4$. A la llamada de la trompeta -la voz cantante del todopoderoso grupo del viento metal- la orquesta en pleno se lanza como una locomotora desbocada. El vuelco armónico (de Sol mayor a Mi mayor, tonalidades no próximas) es directo, sin ningún proceso de modulación. La nueva indicación metronómica es vertiginosa (negra = 152-Allegro Vivace), más aún cuando el tempo anterior era un apacible Andante (corchea = 76). Un factor especialmente relevante es la indicación de intensidad: la música pasa de un prolongado pianissimo, con algún sobrio regulador intermedio, a un fortissimo sin preparación en la trompeta solista, al que sigue el de la orquesta, porque Rossini no escatimó recurso sonoro alguno para reforzar el efecto de contraste radical. Con toda probabilidad cuando compuso esta Obertura el compositor italiano no tenía en mente plasmar artísticamente ninguna máquina de coser ni evolución histórica del sonido, sino solamente escribir música inspirada que atrajese la atención de los oyentes parisinos en el número inicial de la ópera. Sin embargo el autor también se debe a su tiempo; sin pretenderlo forma parte del entorno aural al que pertenece, y que se verá reflejado de una forma u otra en la música que escriba. En suma, no es posible demostrar empíricamente una hipótesis causal como la que plantea Alier, pero ésta resulta coherente y plausible. 

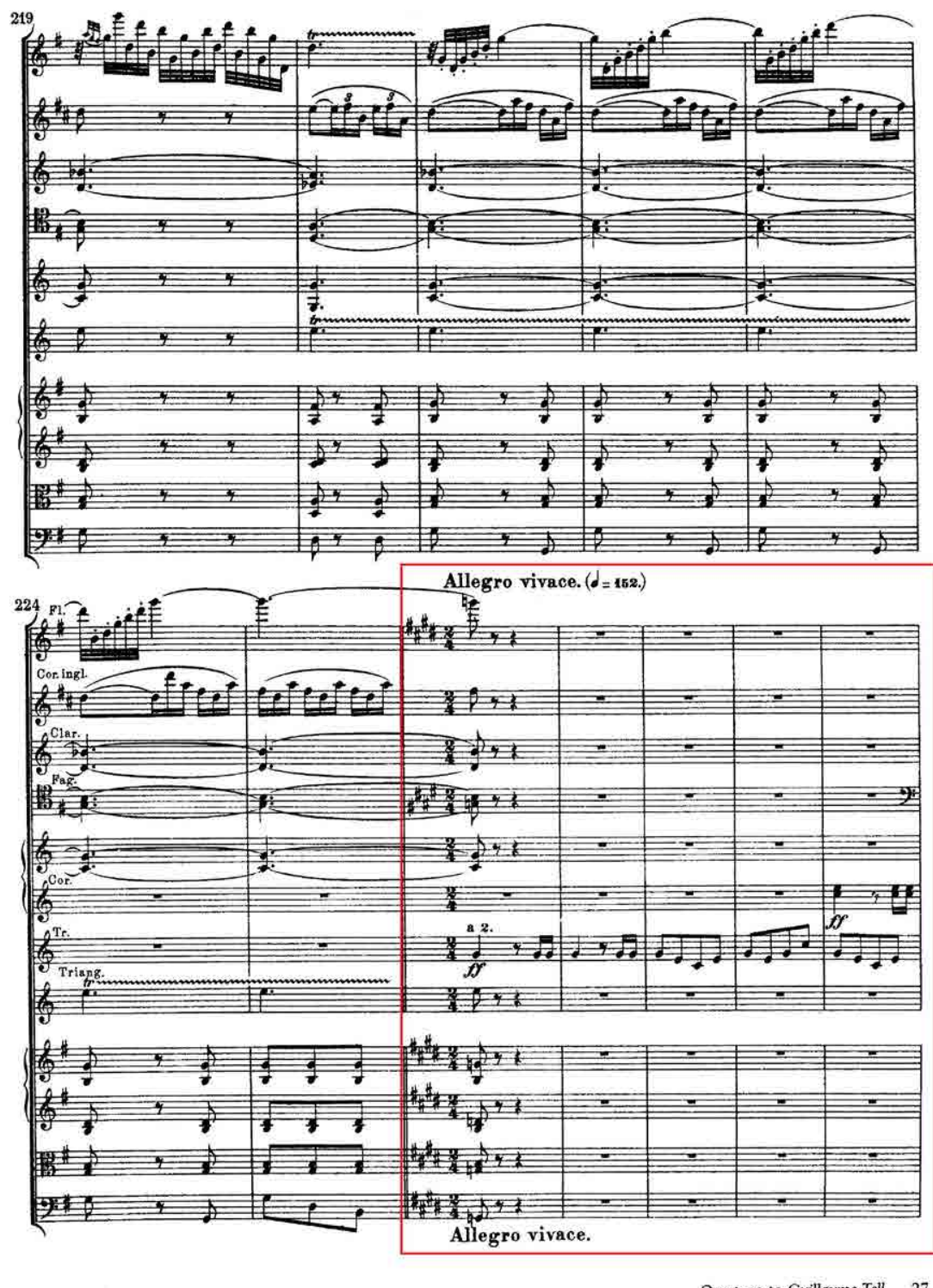

Overture to Guillaume Tell

Figura 7. G. Rossini, Obertura de Guillermo Tell (1829). Compases $219-230 .{ }^{16}$ El subrayado es nuestro.

A lo largo de todo este estudio el aumento de potencia sonora aparece una y otra vez como signo distintivo de la música del siglo XIX. Fue sin duda uno de los grandes cambios que trajo consigo la época. $\mathrm{Al}$ proceder comparativamente, el hecho resulta aún más patente: en la música de Bach (1685-1750) sólo hay tres indicaciones para el matiz fuerte, de las cuales una es simplemente forte, y las otras dos son de

${ }^{16}$ Partitura en Rossini (1994, p. 27). 
menor intensidad (poco forte y mezzo forte), mientras que para los sonidos débiles - piano- Bach emplea hasta cinco matices variados, siendo dos de ellos aumentativos. Y es que en el mundo sonoro de Bach no había sonidos estruendosos ni contrastes súbitos salvo ocasionales excepciones; de ahí que el oído se concentrara de manera natural y sin divergencias extremas en los matices tenues, por oposición a lo que sucedería un siglo después:

\begin{abstract}
Although the dynamic markings in the sources for the St Matthew Passion are not especially prolific and fail fully to mirror such a range, leaving much for performers to add according to early eighteenthcentury taste, Bach consistently emphasises subtlety of nuance over sheer volumen (Lawson y Stowell, 2004, p. 108).
\end{abstract}

La uniformidad característica de la maquinaria industrial se instaló gradualmente en la estética del siglo XIX. Los paisajes sonoros urbanos habían llegado a límites esporádicamente ensordecedores, pero asimismo eran estables en el sentido de continuidad acústica. Corelli o Purcell vivieron en un mundo donde los sonidos en general eran fugaces, se interrumpían constantemente para renacer una y otra vez (véase el látigo del cochero, los gritos de niños y vendedores, o el ladrido de un perro). En cambio para el obrero que utilizara maquinaria pesada el ruido pasó a ser una compañía perenne, invariada y quizá obsesiva:

Machines [create] high redundancy sounds. They may be continuous drones (as in a generator); they may be rough edged [...]; or they may be punctuated with rhythmic concatenations (as in weaving or threshing machines) -but in all cases it is the continuousness of the sound which is its predominating feature. The flat continuous line in sound is an artificial construction. Like the flat line in space, it is rarely found in nature. (The continuous stridulation of certain insects like cicadas is an exception) (Schafer, 1994, p. 78).

El repertorio romántico se pobló de regularidad motívica, diseños repetitivos y bordones prolongados. El Preludio a El Oro del Rhin de Wagner constituye un buen ejemplo de ello; se comenta a continuación como muestra de otra ampliación clave de esta época: la del registro.

El tercer rasgo sobresaliente de la transición a una estética musical decimonónica fue la expansión de la escala musical en las frecuencias graves. En efecto, potencia, regularidad y registros graves fueron características 
acusadas de la auralidad industrial. Los tonos más profundos de la orquesta se vieron reforzados en muchas partituras; si en Vivaldi y Mozart prevalecían claramente los sonidos agudos de instrumentos y cantantes, un siglo después sucede prácticamente lo contrario. En esta faceta el influjo de la afinidad sónica resulta claramente palpable, hasta la actualidad:

Al principio la gente oía solamente sonidos de la naturaleza. Con la revolución industrial el panorama comenzó a cambiar: la mayoría de los sonidos que se empezaron a oír eran sonidos de la tecnología. Una característica de los sonidos tecnológicos es su alto contenido en frecuencias graves [...] Hoy en día, en la calle, la mayoría del sonido que oímos es baja frecuencia: camiones, autobuses, coches, sonidos graves, muy profundos, vibración. La música popular de hoy tiene mucho componente de graves: los instrumentos más importantes en el pop son el bajo y la batería; si tocas el piano tocas la parte grave, no la aguda (Schafer, 1997, p. 85).

En las ciudades y áreas de producción se alcanzó un "perpetual din" (Smith, 2012, p. 53) típico del mundo contemporáneo, que quedaría reflejado en creaciones musicales donde el sonido es incesante. En el Preludio de $E l$ Oro del Rhin (1854), Wagner reflejó con un inmenso bordón de toda la orquesta una sonoridad inimaginable un siglo antes. En la pieza lo primero que llama la atención son los impactantes graves de los contrabajos, a los que siguen los fagotes, precediendo a su vez al arpegiado de trompas y violoncelos. Es decir, un espectacular despliegue de registros graves sobre el infatigable bordón en Mi bemol mayor, durante cinco minutos a lo largo de 163 compases (figura 8). 
VORSPIEL UND ERSTE SCENE.

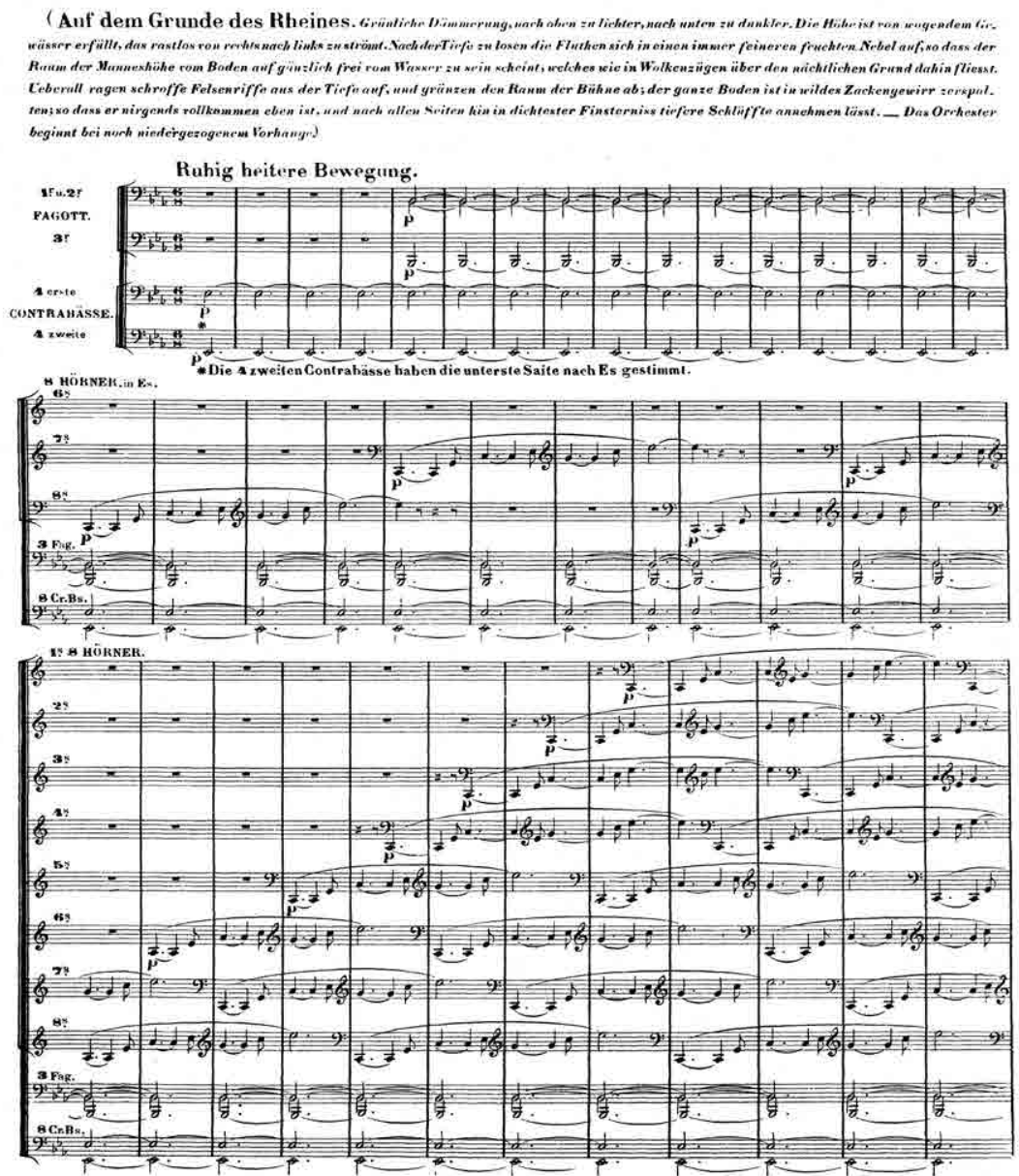

Figura 8. Wagner, Preludio de El Oro del Rhin (1854). Compases 1-40. ${ }^{17}$

Wagner suspende la medida al desvanecer todo acento o señal de modificación; el compás resulta irreconocible, así como el tempo preciso. Suena una música atemporal, una reverberación sonora donde no hay ritmo ni melodía, como una burbuja acústica que crece indefinidamente, nunca explota y en la que el oyente queda atrapado, igual que plausiblemente estaba sucediendo en los espacios sonoros de entonces. Wagner cruzó un umbral compositivo en este Preludio, impensable unas décadas antes. Anticipó el mundo de las bandas sonoras, la recreación monocórdica y la estética de la continuidad variada que se convertiría poco después en el principio basal del minimalismo y otros géneros modernos. ${ }^{18}$

\footnotetext{
${ }^{17}$ Partitura en Wagner (1873, p. 1).

${ }^{18}$ Gustav Mahler fue otro compositor con una sensible tendencia a la suspensión del tiempo, en un continuo musical hipnótico para el oyente (Dolp, 2010).
} 
En acusado contraste con la continuidad sonora descrita, en esta época también sobrevino una convulsa heterogeneidad de paisajes sonoros ante la multiplicidad de generadores de sonidos y espacios de percepción provenientes del mundo industrial y tecnológico, lo que habría estimulado una respuesta en forma de correlativa variedad musical. La música del romanticismo tardío se caracterizó por la tendencia hacia la exploración armónica, que desembocó en una mayor complejidad del tejido musical y concretamente en la tendencia recurrente a la modulación, cambio de modo y uso pródigo del cromatismo. A este respecto es de interés el efecto de percepción auditiva conocido como "Cut out" o corte acústico (Augoyard y Torgue, 2005; Chelkoff, 2011), consistente en el súbito cambio de intensidades, tonos y/o timbres dominantes en el cambio de una sonosfera a otra distinta, como sucede al pasar de una calle a otra, o de un interior de edificio al exterior. Este efecto puede influir bastante en la ulterior configuración de estéticas musicales donde se juega activamente con el factor de la potencia sonora y los cambios temáticos y tonales; ello encajaría con una arquitectura urbana que en el siglo XIX empezó a tener grandes alturas, contrastes interior-calle, y verdaderos muros sonoros de una manzana a otra. Es alrededor de esta profunda metamorfosis del escenario urbano cuando, paralelamente, en la escritura musical se multiplican y subrayan sin límite los contrastes dinámicos y texturales, tanto progresivos como sorpresivos, y cuando se impone un "nerviosismo" notacional que pobló la partitura musical con múltiples matices.

El ámbito melódico no podía permanecer al margen de todas estas radicales transformaciones del discurso musical. También se debe a Wagner el concepto de la "melodía infinita", una ininterrumpida narración melódica que parece, efectivamente, no tener fin y que rompió drásticamente con el hasta entonces hegemónico belcantismo y sus frases "bellas" y acotadas. La melodía infinita puede interpretarse como una fórmula reflexiva de las culturas sonoras igualmente omnipresentes e ininterrumpidas de la era industrial, a modo de flujo graduable pero perenne. Wagner anticipó con este recurso la continuidad temporal de varios géneros musicales del siglo XX.

\section{Conclusiones}

En base al estudio realizado y expuesto en este artículo, hay que subrayar que el siglo XIX fue una etapa crucial de cambios en los paisajes sonoros urbanos del ámbito occidental y consecuente pensamiento estético. La revolución industrial fue fundamentalmente una revolución sonora, tal 
y como se percibió entonces; de ahí la "centralidad" (protagonismo) del sonido y la música en la cultura romántica. Si la música fue tan importante para los europeos del siglo XIX no se debió a un giro histórico azaroso, sino al carácter sonocéntrico que caracterizó a la época, en la que el paisaje cultural (musical) habría sido un heredero directo del acústico. En el pensamiento estético de los compositores tuvo lugar una reacción bipolar: por una parte se produjo un efecto mimético de gigantismo/tremendismo musical, en base a la mímesis sonora respecto del ruidoso entorno industrial. Y por otra parte, debido a un mecanismo compensatorio de evasión o rechazo hacia la degradación ambiental y los excesos del racionalismo ilustrado, se llegó al polo contrario, consistente en buscar refugio en el intimismo y melancolía del romanticismo lírico. Esta paradoja es imprescindible para comprender la naturaleza y articulación del pensamiento romántico.

Destaca objetivamente el crecimiento de la producción instrumental en toda la centuria, mientras que el canto experimentó una cierta regresión en términos comparativos. La voz perdió su secular preeminencia por dos motivos: en primer lugar la fortaleza y regularidad de los entornos acústicos de referencia condujeron a una música cada vez más potente e instrumental. La segunda causa estribó en la "materialidad" o declaración abierta que implicaba la palabra, frente al ideal de belleza pura y abstracción inmaterial que pretendía la música absoluta. El retroceso decimonónico de la voz constituye un tema polémico y en absoluto consensuado; en el presente estudio proponemos que sería el siglo XX, con sus micrófonos, amplificadores y pantallas acústicas de miles de vatios, el tiempo histórico y tecnológico que devolvió a la voz humana su secular primacía entre todas las formas de hacer música, permitiendo al cantante rugir salvajemente o susurrar en trance confidencial en un estadio ante miles de personas.

Regresando al punto de partida de este artículo, la noción de una afinidad sónica entre el individuo y el medio ambiente circundante parece confirmarse suficientemente y tener un margen de aplicación considerable en el campo de la musicología histórica y la etnomusicología. Esta aproximación es complementaria (de ninguna forma excluyente) con los presupuestos y metodología de las musicologías convencionales. Nuestro planteamiento se apoya en que existe una unidad cultural entre la vida y la música que impregna las rutinas diarias en constante interacción e influencia recíproca. En el caso del siglo XIX la mímesis se manifestó en prácticamente todos los parámetros mensurables: regularidad, ritmo, intensidad, modulación, timbre y forma. Significó una metamorfosis integral del discurso musical conocido, cuya estela se prolongó hasta bien 
adentrado el siglo XX, y en determinadas facetas aún permanece. De ahí que la música fuese la primera de todas las artes en el siglo XIX, porque fue una época de formidables cambios acústicos, de los que la música fue a la vez receptora y portavoz popular.

Para terminar, la música no es una esencia fuera de tiempo y lugar, sino que existe estrechamente imbricada en la particular situacionalidad de sus hacedores y receptores, lo que puede conllevar el uso de determinadas aproximaciones para un conocimiento en profundidad que desvele sus facetas menos obvias. En consecuencia, los estudios de sonido y sus aplicaciones devienen hoy en día una auténtica "transdisciplina" (Meelberg et al., 2013), en vista de la variedad e interacción de los diferentes campos disciplinares que contribuyen decisivamente a su desarrollo. Ello explica la complejidad de fuentes y recursos empleados en estas áreas de investigación. Se trata de ciencias que poseen un singular interés por la profundidad y capacidad explicativa de fenomenologías causales subyacentes a los grandes procesos macro-culturales que conforman a escala histórica las sociedades modernas. Por ello, y sin olvidar en modo alguno la fundamental aportación de las musicologías consagradas, constituyen el eje explicativo basal del análisis aquí realizado sobre el siglo XIX como estadio crítico en la historia del pensamiento musical. 


\section{Bibliografía}

» Augoyard, J.-F. and Torgue, H. (Eds.). (2005). Sonic Experience. A Guide to Everyday Sounds. Montreal: McGill-Queen's University Press.

» Bonds, M. E. (1997). Idealism and the Aesthetics of Instrumental Music at the Turn of the Nineteenth Century. Journal of the American Musicological Society, 50(2/3), 387-420.

»Bonds, M. E. (2004). Nineteenth-century Piano Music. Nueva York y Londres: Routledge.

"Boutin, A. (2015). City of Noise. Sound and Nineteenth-Century Paris. Urbana, Chicago y Springfield: University of Illinois Press.

» Brown, C. (2009). El tempo en la música clásica y romántica (1750-1900). Quodlibet, 43, 17-51.

" Campos, J. (2016). Sonic Affinity. Psychology of Music, 44(1), 95-113.

" Campos, J. (2018). “Música y paisajes sonoros: la afinidad sónica como condicionante estético en la creación y percepción de la obra musical". En B. Lolo y A. Presas (Eds.), Musicología en el siglo XXI: nuevos retos, nuevos enfoques. Actas del IX Congreso de la Sociedad Española de Musicología (pp. 1565-1586). Madrid: Sedem.

» Campos, J. y Cea, F. (2019). Daily soundscapes predict musical preferences: A survey on sonic affinity cause-effect processes. Psychomusicology: Music, Mind, and Brain, 29(1), 35-45.

»Chelkoff, G. (2011). A Contribution to the Phono-kinetic Approach: An Architectural Experimentation to Design a Public Shelter. SoundEffects, 1(1), 98-116.

" Cooper, J. (1983). The Rise of Instrumental Music and Concert Series in Paris, 1828-1871. Ann Arbor: UMI Research Press.

»Davies, J. and Lockhart, E. (2017). Introduction. Fantasies of Total Description. En Sound Knowledge: Music and Science in London, 1789-1851 (pp. 1-26). Chicago: University of Chicago Press.

»Dolp, L. (2010). Viennese Moderne and its Spatial Planes, Sounded. 19thCentury Music, 33(3), 247-269.

»Duarte, A. J. (2015). A paisagem cantada como repositório de memória e potenciadora de novas paisagens: o caso da música raiz no Sul de Minas. El Oído Pensante, 3 (1), 7-28.

》Durrell, L. (2017 [1957]). Antrobus. Barcelona: Tusquets.

»Fauser, A. (2005). Musical Encounters at the 1889 Paris World's Fair. Rochester: University of Rochester Press.

» Gawthrop, R. (2012). Thunder and Lightning: Noise, Aesthetics and Audiovisual Avant-garde Practice. En M. Goddard, B. Halligan y P. Hegarty (Eds.), 
Reverberations: The Philosophy, Aesthetics and Politics of Noise (pp. 164-178). Londres: Bloomsbury.

" Girdner, J. H. (1896). The Plague of City Noises. The North American Review, 163(478), 296-303.

" Hecker, T. (2014). The Era of Megaphonics: On the Productivity of Loud Sound, 1880-1930. Montreal: McGill University.

" Horton, J. (2014). Listening to Topics in the Nineteenth Century. En D. Mirka (Ed.), The Oxford Handbook of Topic Theory (pp. 642-664). Oxford y Nueva York: Oxford University Press.

» Jackson, M. (2012). From Scientific Instruments to Musical Instruments: The Tuning Fork, the Metronome, and the Siren. En T. Pinch y K. Bijsterveld (Eds.), The Oxford Handbook of Sound Studies (pp. 201-223). Nueva York: Oxford University Press.

» Larcom, L. (1889). A New England Girlhood. Outlined from Memory. Boston y Nueva York: Riverside Press.

" Lawson, C. and Stowell, R. (2004). The Historical Performance of Music: An Introduction. Cambridge: Cambridge University Press.

» Loughridge, D. (2017). Celestial Mechanisms: Adam Walker's Eidouranion, Celestina, and the Advancement of Knowledge. En J. Davies y E. Lockhart (Eds.), Sound Knowledge: Music and Science in London, 1789-1851 (pp. 4776). Chicago: University of Chicago Press.

" Marx, L. (1964). The Machine in the Garden: Technology and the Pastoral Ideal in America. Oxford: Oxford University Press.

»Meelberg, V., Cobussen, M.; Stewart, S., and Nieuwenhuis, J. (2013). Breaching Sonic Barriers? Sound Studies as a Transdiscipline. Journal of Sonic Studies, 5(1). Recuperado de http://journal.sonicstudies.org/vol05/nr01/a01

» Paddison, M. (2001). Music as Ideal: The Aesthetics of Autonomy". En J. Samson (Ed.), The Cambridge History of Nineteenth-Century Music (pp. 318342). Cambridge: Cambridge University Press.

» Picker, J. (2003). Victorian Soundscapes. Oxford: Oxford University Press.

» Rossini, G. (1994). William Tell and Other Great Overtures in Full Score. Mineola: Dover Publications.

"Samson, J. (2001). The Musical Work and Nineteenth-century History. En The Cambridge History of Nineteenth-Century Music (pp. 3-28). Cambridge: Cambridge University Press.

"Schafer, M. (1994 [1977]). The Soundscape. Our Sonic Environments and the Tuning of the World. Rochester (Vermont): Destiny Books.

»Schafer, M. (1997). Aprender a escuchar para construir nuestro entorno sonoro. Música, Arte y Proceso, 3, 83-97.

»Smith, M. M. (2012). The Garden in the Machine: Listening to Early American Industrialization. En T. Pinch y K. Bijsterveld (Eds.), The Oxford Handbook of Sound Studies (pp. 39-57). Nueva York: Oxford University Press. 
»Tresch, J. (2012). The Romantic Machine: Utopian Science and Technology after Napoleon, Chicago y Londres: University of Chicago Press.

" Trower, S. (2012). Senses of Vibration: A History of the Pleasure and Pain of Sound. Londres y Nueva York: Continuum.

»Wagner, R. (1873). Das Rheingold. Mainz: B. Schott's Söhne.

»Walton, B. (2007). Rossini in Restoration Paris: The Sound of Modern Life. Cambridge: Cambridge University Press.

»Werrett, S. (2015). Disciplinary Culture: Artillery, Sound, and Science in Woolwich, 1800-1850. 19th-Century Music, 39(2), 87-98.

\section{Agradecimientos}

Para la elaboración de gráficos y tratamiento de imágenes en este trabajo, ha sido muy valiosa la ayuda de Diana Campos Presas.

\section{Biografía / Biografia / Biography}

\section{Javier Campos Calvo-Sotelo}

Es licenciado en Geografía e Historia (UAM, 1985), y posee el Grado Profesional de Música (RCSMM, 1993). En 2008 se doctoró en Historia y Ciencias de la Música (UCM). Desde entonces ha formado parte de diversos grupos y proyectos de investigación, en varias especialidades. En el ámbito de los estudios de percepción sonora, es miembro de la SMPC (Society for Music Perception and Cognition) y la ESSA (European Sound Studies Association). Campos desarrolló la teoría de la afinidad sónica a partir de un largo proceso de investigación que incluyó la colaboración de especialistas como A. Cohen, M. Cumberland, R. Parncutt, y A. Lamont, publicando en 2016 los primeros resultados en Psychology of Music. 